\title{
WHAT MOTIVATES RESTAURANT CUSTOMERS TO TIP: EVIDENCE FROM THE CZECH REPUBLIC
}

\author{
Michal Kvasnička \\ 'Department of Economics, School of Economics, Masaryk University, Žerotínovo nám. 617/9, 60177 Brno, the \\ Czech Republic
}

\begin{abstract}
KVASNIČKA MICHAL. 2018. What Motivates Restaurant Customers to Tip: Evidence from the Czech Republic. Acta Universitatis Agriculturae et Silviculturae Mendelianae Brunensis, 66(1): 0273-0282.

Although the literature on tipping is enormous, it is still unclear what motivates people to tip. In particular, it is unresolved how tips depend on service quality, patronage frequency, and group sizes, why people tip more for better service if they do, and why they tip at all when they can avoid it. This study aims to fill this gap. It uses survey data to explore what motivates Czech restaurant customers to tip. Reasons for tipping, factors constituting service quality, and reasons for tipping more for better service are explored by descriptive statistics. The impact of service quality, group size, and patronage frequency on tips is assessed by random effects estimator and simple policy capturing. The results show that Czech customers tip mostly because of gratitude, to follow the social norm, and to avoid feeling guilty when not tipping. Most Czechs do not tip to supplement waiters' wages. Their tips are strongly influenced by service quality, which includes the whole experience of a dinner in a restaurant and not only the waiter's performance. They reward a good service because it is fair, out of gratitude, and to motivate the waiters to provide good service in the future, but not because it is prescribed by social norms. On the other hand, there is little evidence that their tips depend on patronage frequency or group size.
\end{abstract}

Keywords: tipping, motivation, social norms, gratitude, social pressure, strategic behavior, service quality, patronage frequency, restaurants, the Czech Republic

\section{INTRODUCTION}

Tipping is puzzling behavior. Since tips are paid after the service is delivered and are not legally enforceable, self-interested agents should never tip unless they repeatedly interact with the same waiter. Yet most people tip even in one-off interactions, which suggests that tipping is influenced by social norms and psychological factors rather than economic calculation. However, tipping is economically important too. Azar (2007b) claims that the total amount tipped is around 27 billion USD a year in US restaurants alone. Tipping may also have important managerial consequences: it can be a substitute for managerial supervision over tipped employees if customers tip significantly more for excellent service than for mediocre.

Even though the literature on tipping is enormous, some questions still remain unresolved.
The most important unresolved questions include: how tips depend on service quality, on the frequency with which customers encounter particular servers, on customer group sizes, and why people tip at all when they can avoid it. In other words, what motivates people to tip? Traditional empirical research methods based on exit survey data have provided mixed results, possibly because of the endogeneity of service quality, selection bias, and differences between individuals. For these reasons some researchers, e.g. Kahneman, Knetsch, and Thaler (1986), Bodvarsson and Gibson (1999), Rogelberg et al. (1999), and Azar (2010b), have adopted another approach: a hypothetical survey. In these surveys, researchers ask respondents directly how much they would tip in various hypothetical situations and what motivates them to tip. The experiment-like structure of the surveys 
eliminates problems with endogeneity, selection bias, etc.

The literature on tipping is extensive and two excellent reviews have been already provided by Lynn (2006) and Azar (2007b). Therefore, I will focus here only on general results concerning the three determinants of tips explored in this study - service quality, patronage frequency, and group size - in the USA, Canada, and Israel. I will review the methods and results of the three studies which I follow more closely, Bodvarsson and Gibson (1999), Rogelberg et al. (1999), and Azar (2010b), in more detail in the Materials and Methods. I will summarize what is known about restaurant tipping in the Czech Republic too.

Theoretical models predict that customers will tip more when service quality is better, see e.g. Azar (2007a). However, exit surveys have found a weak or nonexistent relationship between service quality and tip size. Lynn and Latané (1984) found no relationship. Bodvarsson and Gibson (1997) found a positive relationship in five out of seven restaurants but a negative one in the two other restaurants; the relationship was positive on average but very weak over all seven restaurants. Lynn and McCall (2000) found so weak a positive relationship that they doubted waiters would notice it in their earnings. Lynn (2003) found a very weak relationship, and so did Azar (2009). On the other hand, two hypothetical surveys found that customers tip significantly more for better service, see Bodvarsson and Gibson (1999) and Azar (2010b). Rogelberg et al. (1999) found by means of policy capturing on hypothetical survey data that some customers tip more for better service while others do not. There are several explanations of the discrepancy between the results of hypothetical and exit surveys. Bodvarsson and Gibson (1994) claim that the relationship between tip size and service quality cannot be estimated from exit survey data because the variability of quality measures is too small since only well-performing waiters can survive in an industry where tips are their major source of income. Azar (2007b) offers two other explanations: 1) Customers want to tip based on service quality, but they succumb to the pressures of social norms at the restaurant. 2) Service quality is endogenous - waiters can guess how much a particular customer will tip and adjust their efforts accordingly - and hence its impact cannot be assessed by OLS. The latter explanation is consistent with the findings of Bodvarsson and Gibson (1994), who corrected for service quality endogeneity and found a strong relationship between tip size and service quality in their exit survey data. Barkan and Israeli (2004) provided direct evidence of service quality endogeneity.

Economic theory also predicts that a self-interested agent should not tip unless she interacts with a waiter repeatedly. When the social norm of tipping is taken into account, economic models predict that all customers tip but regular patrons tip more and with more sensitivity to service quality than one-off customers, see e.g. Azar (2007a). The empirical results are mixed. Several exit-survey studies found that the regular patrons tip more than one-off customers, see Lynn and Grassman (1990), Lynn and McCall (2000), Conlin, Lynn, and O'Donoghue (2003), Bodvarsson and Gibson (1994), Azar (2007a), and Azar (2010a). On the other hand, Bodvarsson and Gibson (1997) found the relationship statistically significant only in two out of seven restaurants, and even there it was small. Hypothetical surveys found no relationship between tips and patronage frequency, see Kahneman, Knetsch, and Thaler (1986) and Azar (2010b). A possible explanation is that patronage frequency does not significantly affect tipping behavior, but serves as a proxy for a missing variable, most likely for unobserved customer incomes which are correlated with tips, see Azar (2010b). Azar (2010b) also found that regular patrons do not tip with greater sensitivity to service quality than one-off customers.

Economic theory does not make clear predictions as to how tips are influenced by the size of groups dining together, see Lynn (2006) or Azar (2007b). Customers dining in bigger groups may tip more because of the stronger social pressure, or less because customers' responsibility is more diffused in bigger groups. It is also easier for waiters to serve groups than individuals seated separately. Moreover, if customers pay together in groups, the magnitude effect $^{1}$ can lower the percentage tip. The empirical results are mixed. Freeman et al. (1975), Lynn and Latané (1984), Bodvarsson and Gibson (1997), and Bodvarsson and Gibson (1999) found that tips decrease with group size. Lynn and Grassman (1990) and Azar (2010a) found no relationship. Conlin, Lynn, and O'Donoghue (2003) found that customers tip more when in bigger groups.

Tipping in the Czech Republic has been studied by Kvasnička and Szalaiová (2015). Czech restaurant customers tip about $7 \%$ of their bills and raise their tips with bill size. They tip more for better service too (however, this result is only tentative because customers' rating of service quality was not directly observed and was substituted for by a proxy). Group size lowers the percentage tip when the customers pay together. Surprisingly, regular patrons tip significantly less and even withhold tips altogether more often than non-regular customers. There are differences between genders too: male customers tip more than female customers and female waitresses earn more than male waiters. Czech customers tip by rounding up the bill to a round number, rather than by leaving a separate tip (tipping evolved from

1 The magnitude effect occurs when tips as a percentage of bills decrease as bills increase. It can be caused e.g. by rounding, flat tipping (i.e. tipping dollar amounts instead of tipping a percentage of bills), etc. 
letting waiters to keep the small change in the Czech Republic). This creates a positive intercept when regressing tips in CZK on its covariates, and hence the magnitude effect.

This study explores the four puzzling questions stated above with a special emphasis on the impact of service quality. Methodologically it builds on the research of Bodvarsson and Gibson (1999), Rogelberg et al. (1999), and Azar (2010b). It uses data from a new hypothetical survey carried out in the Czech Republic. The study contributes to the previous research in two ways. First, it provides evidence from a new country. So far, empirical studies on tipping have focused on the USA, Canada, and Israel. Evidence from the Czech Republic is of interest because this country has undergone other developments, and tipping probably has different origins here. Second, in comparison with previous research based on hypothetical reviews, this study utilizes more systematically both between and within information present in the data and focuses both on aggregate statistics and on individual behavior.

\section{MATERIALS AND METHODS}

In this section, I will first introduce data used in this study and then explain my methodology. Since my approach is closely related to methods in the previous literature, I will first summarize the methods and results of the work I follow, and then explain how my approach differs from the previous one and what procedures are used to analyze data. Description of methods is divided into subsections that correspond to the question explored: first, what motivates customers to tip; second, what determines how much the customers tip focusing on service quality, patronage frequency, and group size; third, how individual customers' tipping strategies differ from each other; and fourth, why customers tip more for better service and what constitutes a good service. I will keep this structure in the following sections too.

\section{Data}

Respondents in previous hypothetical surveys were overwhelmingly university students. Therefore, to be comparable, data used in this study was obtained by surveying students too. The respondents were the students enrolled in the Principles of Microeconomics course at Masaryk University School of Economics in the fall of 2014. Most these students were freshmen while the rest were sophomores that had not passed the exam in their first year and also several were students of other schools at Masaryk University. The students were asked whether they tip when eating in restaurants, for what reasons they tip, what factors determine their tips, how much they would tip in twelve hypothetical situations which differed in group sizes (dining alone or with a friend), patronage frequency (dining in a restaurant they will not revisit or where they dine frequently), and in three levels of service quality, why they tip more when waiters provide better service (if they do), and their characteristics (gender, type of study, nationality, and their actual customer frequency). The whole questionnaire will be provided on request.

The survey was taken in April 2015, several months after the students finished the course. It produced 233 completed forms. However, some observations were eliminated for two reasons. First, to study tipping in the Czech Republic and to get respondents of a similar kind as in the previous research, the set of respondents was limited to the Czech and Slovak students of economics at Masaryk University - all responses from foreigners (except Slovaks ${ }^{2}$ ) and students of other schools were excluded from the dataset. Second, several respondents stated their tips obviously incorrectly (they claimed to tip more than $100 \%$ of the bill; it seems they filled in the bill plus tip instead of the tip alone). Their responses were also eliminated from the dataset. After this elimination, the dataset consists of 197 respondents.

The structure of the dataset is as follows. Out of the 197 respondents, 112 were women and 85 were men. 165 respondents visit restaurants at least twice a month and of these 71 respondents eat in restaurants at least twice a month (I denote the latter 71 respondents as regular customers). The test indicates that gender and customer frequency are independent ( $p$-value is 0.61). As noted above, Czech customers usually use tips to round up the bill to tens of CZK. This rounding up is also apparent in the dataset. Since the bill size was $200 \mathrm{CZK}^{3}$ in all treatments, most respondents stated they would tip rounded figures like 0, 10, 20 CZK etc. Out of all 2,364 tips stated by all respondents in all hypothetical situations, 2,158 tips (i.e. 91.3\%) were rounded up.

\section{Methods Used to Assess Reasons for Tipping}

Hypothetical surveys allow us to ask respondents why they tip. Bodvarsson and Gibson (1999) asked their respondents (the US and Canadian students) to mark any number of the following three reasons for tipping: 1) to supplement waiters' incomes, 2) to reward waiters' service (i.e. to tip out of gratitude), and 3) because it is "right thing to do". The most important reason for tipping both in the USA and Canada was to reward waiters for their service, i.e. gratitude.

2 The Czech and Slovak people are treated together because the two nations have very similar language and culture, were until recently part of one country, and there are many Slovaks living and studying in the Czech Republic.

$3200 \mathrm{CZK}$ is a price of a decent dinner in a Czech restaurant. Depending on the current exchange rate, it is between 8 and 10 USD. 
It was marked by $77 \%$ of Americans and $81 \%$ of Canadians (the latter including visiting students). Supplementing waiters' income was the second most important reason for tipping in both countries, marked by $70 \%$ of Americans and $61 \%$ of Canadians. The "right thing to do" was minor - it was marked by $25 \%$ of respondents in both countries. Bodvarsson and Gibson (1999) noticed some differences between regular and non-regular customers in the USA. First, $81 \%$ of regular customers (in comparison with $64 \%$ of non-regular ones) tip to reward good service. Second, 68\% of regular customers (in comparison with $46 \%$ of non-regular ones) tip to supplement waiters' incomes. However, no similar difference was observed in Canada.

Azar (2010b) asked his respondents (US and Israeli students and a few Israeli off-college young people) to mark any number of seven possible reasons for tipping. These reasons included feeling guilty or embarrassed when not tipping, following social norms, showing gratitude to waiters, supplementing waiters' low wages, and avoiding the risk that the waiters would provide worse service on the next encounter or would yell at the customer when not tipped. The most important reason for tipping in the USA was compliance with social norms, marked by $85 \%$ of US respondents. The other important reasons included gratitude (68\%), supplementing waiters' wages (67\%), and feeling guilty $(60 \%)$ and embarrassed (44\%). The same five reasons were important also in Israel though in a slightly different order and with lower magnitudes. The most important reason for tipping in Israel was gratitude (69\%), followed by compliance with social norms (58\%), supplementing waiters' wages (32\%), and feeling embarrassed (23\%) and guilty (13\%). The last two reasons were only marginal in both countries: tipping to avoid the risk of worse future service was marked by $14 \%$ of Americans and $3 \%$ of Israelis, the risk of yelling by $4 \%$ of Americans and no Israeli. On average, Americans marked 3.42 and Israelis 1.98 reasons for tipping. Azar (2010b) divided these reasons into positive and negative ones. Positive reasons are those where "good outcomes... happen when one tips", negative reasons are those where "negative outcomes ... happen when one does not tip" (p. 425). He included tipping to show gratitude, to comply with social norms, and to supplement waiters' low wages among positive reasons, and the rest among negative ones. In both countries, respondents tip more for positive rather than negative reasons. The ratio of positive to negative reasons was 2.4 in the USA and 5.45 in Israel.

In this study, respondents were also asked whether and why they tip. The reasons for tipping were chosen to closely resemble the reasons used by Azar (2010b) and were only slightly modified to take into consideration the Czech language and culture. They included tipping because 1 ) it is a custom and it is expected (i.e. a social norm), 2) it is a reward for waiters' service (i.e. gratitude), 3) waiters earn low wages and depend on tips, 4) waiters could be nasty when not tipped (i.e. retaliate immediately); I have made the wording less expressive and more general than the risk that a waiter would yell at a customer because no one I discussed the question with could imagine that this could happen), 5) the waiter could be nasty or provide worse service on the next encounter when not tipped (i.e. future retaliation), 6) people around would look at the customer askance (i.e. social pressure; there is no equivalent in Azar's questionnaire; I have added this option to distinguish between following the social norms through belief and following them to avoid social punishment), and 7) to avoid feeling guilty when not tipping (Azar has separated feeling guilty and embarrassed but the terms are closely related in Czech). As in the previous research, this part is only descriptive. The goal is to find out for what proportion of respondents is a given reason to tip important. Differences between genders and regular and non-regular customers are assessed with non-parametric Wilcoxon and Kruskal - Wallis tests which test whether both samples have the same mean and come from the same distribution respectively.

\section{Methods Used to Explore Determinants of Tip Size}

To explore the impact of service quality, group size, and patronage frequency, the respondents of previous surveys were asked how much they would tip in several hypothetical situations. Bodvarsson and Gibson (1999) asked their respondents how much they would tip in six situations which differed in service quality (poor, satisfactory, and very good) and group size (dining alone or with a friend). The bill size was $\$ 10$ where the customer dined alone and $\$ 20$ where she dined with a friend (it was assumed the customers pay together). They found that customers tip significantly more for better service both in the USA and Canada (for instance, Americans tip $6.5 \%$ for poor service, $14.3 \%$ for satisfactory service, and $21 \%$ for very good service when dining alone). Customers also tip slightly more when alone than with a friend.

Azar (2010b) asked each respondent how much she would tip in five situations that differed only in service quality (quality levels 1 and 5 were framed as "poor service" and "excellent service" respectively). Azar used a between-subject design and distributed other treatments randomly among respondents. These treatments differed in group size (dining alone or with a friend) and patronage frequency (dining at the restaurant only once, once a month, or once a week). Each customer's part of the bill was \$10 in all cases (the respondent and her friend paid separately). Azar analyzed the results in two ways. First, he explored the determinants of average tips (the average of the five answers of each respondent) by regressing the average tips on patronage frequency, group size, the number of reasons for tipping, and individual reasons for 
tipping. In this way, the impact of service quality could not be analyzed, and only the between information present in the data was used. Second, he explored the impact of service quality on tips by comparing the mean tips for every service quality level. He only partially confirmed the previous results. Tips rose significantly with service quality both in the USA and Israel, but there was no difference in tips due to group size or customer frequency. Customers with more reasons for tipping tipped more than customers with fewer reasons for tipping. Two individual reasons for tipping raised tips significantly (at a confidence level of $10 \%$ or less): social norms and gratitude in the USA and gratitude and supplementing waiters' incomes in Israel and in combined data for both countries together.

In the present study, the respondents were asked how much they would tip in twelve situations that differed in service quality (poor, satisfactory, or very good), customer frequency (dinner in a restaurant the customer will not revisit in the near future or dinner in a restaurant the customer visits at least twice a month), and group size (the customer dines alone or with a friend who is not her partner). In all situations, each person paid separately a bill of 200 CZK per person. Three quality levels were used to make the differences between quality levels more salient and to lower the number of questions the respondents had to answer. The differences between the levels have to be salient because most Czech customers tip in multiples of ten CZK when the bill is rounded, and barely noticeable differences could result in the same tips due to the rounding. Two levels of patronage frequency were used for the same reason. Since each respondent stated her tips in all twelve treatments (i.e. the dataset has a panel structure where one dimension is a person and the other is a situation), both the between and within information can be utilized, and the impact of service quality can be estimated directly with the random effects estimator, a panel econometric technique that controls for unobserved heterogeneity.

\section{Methods Used to Analyze Individual Tipping Strategies}

Both the previous literature and the results of the tests presented above suggest that there might be differences between the tipping strategies of the individual respondents. One way to assess these differences is policy capturing. In this method, one regression is run for each respondent. The internal consistency of a respondent's strategy (her "policy function") can be assessed by the individual regression's - the higher it is the more consistent the strategy is. Rogelberg et al. (1999) used policy capturing to assess individual differences in tipping behavior and found that individual tipping strategies are fairly consistent - the median was around $80 \%$. All tipping strategies were linear. Most customers reacted to two to four factors, usually bill size (95\% of respondents), service quality (44\%), waiter friendliness (34\%), and food quality (22\%).

Data obtained in in this study allow for simplified policy capturing too. Each respondent's tips in the twelve hypothetical situations are regressed separately on four dummies (dinner with a friend, dinner in a frequently visited restaurant, poor service, and very good service) and on the intercept. Instead of constructing clusters of similar tipping strategies, I will only ask whether each factor increases, decreases, or does not change tips. It decreases tips if the corresponding regression parameter is negative and statistically significant at a significance level of $10 \%$. It increases tips if the parameter is positive and statistically significant. It does not affect tips if the parameter is insignificant or, for numerical stability, at an absolute value lower than.

\section{What Good Service Is and Why Customers Tip More For It}

Since customers usually tip more for better service, it is interesting to know what constitutes good service and why customers tip more for it. Bodvarsson and Gibson (1999) asked their respondents to mark any number of five measures of service quality that are fairly often used in the literature (waiters' promptness, friendliness, attentiveness, appearance, and the amount of work done) and one factor beyond waiters' control (quality of meal). The four most important determinants of service quality were friendliness (marked by $99 \%$ of Americans and $98 \%$ of Canadians), promptness (marked by 95\% respondents in both countries), attentiveness (marked by $90 \%$ of Americans and $94 \%$ of Canadians), and the amount of work done (79\% in the USA and 76\% in Canada). The last reason, waiters' appearance, was much less pronounced - it was marked by $62 \%$ of Americans and $56 \%$ of Canadians. Food quality was marked by $79 \%$ of Americans and $70 \%$ of Canadians. There were some differences between regular and non-regular customers too. Waiters' appearance was less important for regular customers than for non-regular ones in both the countries. The amount of work done was less important for regular customers than for non-regular ones in the USA but not in Canada. In this study, respondents were asked the same question as in Bodvarsson and Gibson (1999). One more quality factor (waiters' politeness) and one more factor beyond waiters' control (restaurant appearance and cleanliness) was added too.

When we know what factors the customers appreciate, it is interesting to know why they reward them with higher tips when they are not obliged to do so. Azar (2010b) asked his respondent to mark any number of the following reasons for why they tip more for better service (if they do): 1) to show their gratitude for the service, 2) because they believe it is fair to tip more for better service than for worse, 3) because social norms dictate tipping more for better service, or 4) to teach waiters to perform well. The two most important reasons were showing gratitude and fairness: $81 \%$ of 
Americans and 55\% of Israelis indicated they tip more for better service to show gratitude, 74\% of Americans and $61 \%$ of Israelis indicated they tip more for better service because it is fair. The other two reasons are much less important in both countries. Only $40 \%$ of Americans and $36 \%$ of Israelis tip more to teach waiters to serve well, and $32 \%$ of Americans and $6 \%$ of Israelis believe that social norms require tipping more for better service. In this study, the respondents were asked the same question.

Both these questions are only descriptive. The goal is to find out what proportion of respondents agrees with the statement. Differences between genders and regular and non-regular customers are again assessed with non-parametric Wilcoxon and Kruskal-Wallis tests.

\section{RESULTS}

In this section, I will summarize the results of this study. I will follow the same structure as described in Materials and Methods.

\section{Reasons for Tipping}

All respondents in our dataset claimed that they, in general, tip when they dine in restaurants (however, 2 out of 197 respondents stated zero tips in all the situations given later in the survey). The reasons why Czech customers tip are summarized in Tab. I. The two most important reasons for tipping are to reward waiters for their service, i.e. gratitude, $(85.8 \%$ of respondents marked that reason) and to maintain the custom, i.e. the social norm (78.7\%). The third and fourth reasons for tipping (to avoid feeling guilty, $37.6 \%$, and social pressure, $23.4 \%$ ) are much less pronounced. Other reasons are marginal. There are few differences between genders: men fear that waiters may retaliate now or later when not tipped more than women ( $p$-values of the differences are 0.046 and 0.04 respectively) and feel greater social pressure too ( $p$-value of the difference is 0.055). There are some differences between regular and non-regular customers as well: regular customers pay less attention to social pressure ( $p$-value of the difference is 0.033 ) and perhaps also fear less that waiters may retaliate now or later (both $p$-values are 0.08). Positive reasons (reasons $1-3$ ) predominate in the Czech Republic: the ratio of positive to negative reasons here is 3. Interestingly, women and regular customers tip more because of positive reasons than men and non-regular customers (both Wilcoxon and Kruskal-Wallis tests indicate that the differences are statistically significant with $p$-values 0.002 and 0.05 respectively for the difference between genders and 0.007 and 0.037 respectively for the difference between regular and non-regular customers).

\section{Determinants of Tip Size}

Factors influencing tip sizes are summarized in regression Tab. II. The dependent variable is tip size in CZK. All regression models show that service quality affects tips strongly and statistically significantly: poor service lowers tips by about 10 CZK (i.e. about $5 \%$ of the bill) while very good service raises them by about the same amount in contrast to satisfactory service. Dining with a friend and repeated visits raise tips too but to a much smaller degree. Since most respondents stated their tips in rounded multiples of ten CZK, parameters much smaller than $10 \mathrm{CZK}$ indicate that only some respondents in some situations tipped more when with a friend or in a restaurant they visit often. (Differences among individuals are further explored in the next section.)

In the regression models in Tab. II, three covariates were controlled for: respondents' gender, actual customer frequency, and respondents' reasons for tipping. While there is no significant difference between genders, regular customers tipped significantly more than non-regular customers. However, since the parameter is much lower than $10 \mathrm{CZK}$, it seems that only some regular customers tipped more than non-regular ones. Respondents with more reasons for tipping tipped more than customers with fewer reasons for tipping. Tips are most strongly influenced by three reasons: reward for good service (significant at a confidence level of $5 \%$ ), social norms, and fear of future retaliation (both significant at 10\%); there is little evidence

I: Reasons fortipping.

\begin{tabular}{lccccc}
\hline & all & women & men & regular & non-regular \\
\hline 1. social norm & $78.7 \%$ & $83 \%$ & $72.9 \%$ & $73.2 \%$ & $81.7 \%$ \\
2. gratitude & $85.8 \%$ & $88.4 \%$ & $82.4 \%$ & $91.5 \%$ & $82.5 \%$ \\
3. to supplement low wages & $10.7 \%$ & $10.7 \%$ & $10.6 \%$ & $14.1 \%$ & $8.7 \%$ \\
4. to avoid immediate retaliation & $6.1 \%$ & $2.7 \%$ & $10.6 \%$ & $1.4 \%$ & $8.7 \%$ \\
5. to avoid future retaliation & $11.7 \%$ & $7.1 \%$ & $17.6 \%$ & $5.6 \%$ & $15.1 \%$ \\
6. to avoid social pressure & $23.4 \%$ & $17.9 \%$ & $30.6 \%$ & $14.1 \%$ & $28.6 \%$ \\
7. to avoid guilt & $37.6 \%$ & $40.2 \%$ & $34.1 \%$ & $38 \%$ & $37.3 \%$ \\
\hline number of reasons & 2.54 & 2.5 & 2.59 & 2.38 & 2.63 \\
\hline average for positive reasons & $58.4 \%$ & $60.7 \%$ & $55.3 \%$ & $59.6 \%$ & $57.6 \%$ \\
\hline average for negative reasons & $19.7 \%$ & $17 \%$ & $23.2 \%$ & $14.8 \%$ & $22.4 \%$ \\
\hline positive to negative reasons ratio & 3 & 3.6 & 2.4 & 4 & 2.6 \\
\hline
\end{tabular}


that customers who claim they tip to supplement waiters' low wages do actually tip more than others. Interestingly, Model (3) shows it is only infrequent customers who claim they tip more in often visited restaurants (sum of coefficients of repeated visits and of interaction between repeated visits and regular patrons is insignificantly different from zero with $p$-value 0.5).

\section{Individual Tipping Strategies}

The policy capturing provided 197 individual regressions with minimum equal to 45.7 and median equal to 96.2. The inspection of individual tipping strategies shows that most respondents $(79.7 \%)$ tip the same when in a restaurant they visit often as in restaurants they never revisit. Far fewer respondents (15.2\%) tip more when in a restaurant they visit often. Surprisingly, $7.1 \%$ of respondents tip less when in restaurants they visit often. Similarly, most respondents (82.7\%) tip the same when they dine with a friend as when alone. Many fewer respondents (15.7\%) tip more when with a friend and still fewer respondents (3.6\%) tip less when with a friend. The picture is different with service quality. Respondents use only four strategies to respond to service quality. The most often used strategy is to tip less for poor service and more for very good service compared to satisfactory $(74.1 \%$ of respondents follow this strategy). Other strategies are much less common: $14.2 \%$ of respondents tip the same for satisfactory and very good service but less for poor service, $8.1 \%$ of customers tip the same for poor and satisfactory service but more for very good service, and only $3.5 \%$ of customers (including two respondents who never tip) tip the same for each service quality. The most common full strategy (adopted by $52.8 \%$ of respondents) is to tip the same when alone as when with a friend, the same with no regard to patronage frequency, less for poor service, and more for very good service. The strategy suggested by overall data (Tab. II), i.e. tipping more with a friend, more in a revisited restaurant, less for poor service, and more for very good service, was adopted only by $3.6 \%$ of respondents.

What Good Service Is and Why Customers Tip More For It

What constitutes good service is summarized in Tab. III. Most respondents are willing to reward waiters' attentiveness, politeness, friendliness, and promptness. The other two reasons (the amount of work done and waiters' appearance) are considered by fewer respondents. There are almost no differences between genders or regular and non-regular customers. The only significant difference lies in how customers respond to waiters' appearance. While $40 \%$ of men consider it when deciding how much to tip, only $14.3 \%$ of women do so ( $p$-value of the difference is well

II: Regression analysis of determinants of tips. The dependent variable is tips in CZK. Coefficients are estimated by random effect estimator. Robust standard deviations are reported in parentheses.

\begin{tabular}{|c|c|c|c|}
\hline & $(1)$ & $(2)$ & (3) \\
\hline gender $=$ male & $0.26(0.88)$ & $0.46(0.86)$ & $0.46(0.86)$ \\
\hline regular customer & $2.16^{* *}(0.96)$ & $2.01^{* *}(0.98)$ & $2.09^{* *}(1.01)$ \\
\hline with friend & $1.43^{* * *}(0.26)$ & $1.43^{* * *}(0.26)$ & $1.21^{* * *}(0.30)$ \\
\hline repeated visits & $0.98^{* * *}(0.28)$ & $0.98^{* * *}(0.28)$ & $1.37^{* * *}(0.37)$ \\
\hline quality = poor & $-10.38^{* * *}(0.39)$ & $-10.38^{* * *}(0.39)$ & $-9.98^{* * *}(0.51)$ \\
\hline quality = very good & $10.57^{* * *}(0.53)$ & $10.57^{* * *}(0.53)$ & $10.01^{* * * *}(0.60)$ \\
\hline number of reasons to tip & $1.29^{* * *}(0.39)$ & & \\
\hline reason to tip: social norm & & $1.81^{*}(1.09)$ & $1.81^{*}(1.09)$ \\
\hline reason to tip: gratitude & & $2.19^{* *}(1.11)$ & $2.19^{* *}(1.11)$ \\
\hline reason to tip: low wage & & $1.14(1.16)$ & $1.14(1.16)$ \\
\hline reason to tip: immediate retaliation & & $0.60(1.72)$ & $0.60(1.72)$ \\
\hline reason to tip: future retaliation & & $2.58^{*}(1.38)$ & $2.58^{*}(1.38)$ \\
\hline reason to tip: social pressure & & $0.003(1.09)$ & $0.003(1.09)$ \\
\hline reason to tip: guilt & & $1.33(0.92)$ & $1.33(0.92)$ \\
\hline regul. cust. * repeated visits & & & $-1.08^{* *}(0.55)$ \\
\hline regul. cust. $*$ with friend & & & $0.62(0.59)$ \\
\hline regul. cust. $*$ quality = poor & & & $-1.12(0.79)$ \\
\hline regul. cust. $*$ quality = very good & & & $1.56(1.16)$ \\
\hline (intercept) & $8.72^{* * *}(1.37)$ & $7.72^{* * *}(1.57)$ & $7.69^{* * *}(1.59)$ \\
\hline Observations & 2,364 & 2,364 & 2,364 \\
\hline $\mathbf{R}^{2}$ & 0.65 & 0.65 & 0.66 \\
\hline Adjusted $\mathbf{R}^{2}$ & 0.65 & 0.65 & 0.65 \\
\hline
\end{tabular}

$* p<0.1 ; * * p<0.05 ; * * * p<0.01$ 
below 0.001). Many respondents take into account also food quality and the restaurant's appearance and cleanliness, two factors that are beyond the waiters' control. This might suggest that many Czech customers (especially regular ones) do not tip to reward the waiters' performance only but to reward the whole dining experience.

The reasons why restaurant customers reward waiters with higher tips when the service is better are summarized in Tab. IV. All respondents indicated at least one reason to tip more for better service. Most Czech respondents stated they tip more for better service because it is fair and to show their gratitude. Social norms apparently do not prescribe tipping more for better service in the Czech Republic. Surprisingly, $61.4 \%$ of Czech respondents stated they tip more for better services to teach waiters that their tips depend on service quality.

\section{DISCUSSION}

In this section, I will compare the present results with the results of the three studies I built methodologically on and will discuss some practical implications of the findings. I will also note the limitations of the present study.

Let us start with the reasons for tipping. The results partially confirm what is known from previous studies. As with the US, Israeli, and Canadian customers, Czech customers tip mostly for two positive reasons (gratitude and social norms). It seems that most Czech customers have internalized the social norm and follow it from belief rather than because of social pressure $178.7 \%$ of the Czech customers tip because of the social norm, yet only $23.4 \%$ tip because of social pressure). Feeling guilty when not tipping is also a strong motivation in the
Czech Republic. The major difference between Czech and US, Canadian, and Israeli customers lies in tipping to supplement waiters' incomes. While more than two thirds of US customers, four fifth of Canadians, and third of Israelis tip for this reason, only $10.7 \%$ of Czech restaurant customers do. This difference may be caused by the fact that Czech waiters' incomes consist mostly of payroll, not tips, and that Czech customers know this.

The findings about determinants of the tip sizes partially confirm the previous findings by Bodvarsson and Gibson (1999) and Azar (2010b). The strong influence of service quality is confirmed. The effect of group size is unclear: Bodvarsson and Gibson (1999) found that customers dining in groups tip a smaller percentage than lone customers. Azar (2010b) found no effect. Respondents in this study tipped on average a higher percentage when dining in groups than alone. However, the effect may be caused by a minority of respondents only. Azar's claim that visiting frequency does not influence tip size (found also by Kahneman, Knetsch, and Thaler (1986)) is also confirmed. Regular customers in this study tip the same with no regard to visiting frequency. Non-regular customers claim they would tip more in restaurants they visit often than in restaurants they do not revisit; however, their claim is purely speculative. Azar's claim that people with more reasons for tipping tip more is also confirmed but the individual reasons are slightly different here. The only reasons for tipping statistically significant on a confidence level of $10 \%$ are social norms and gratitude in the USA and gratitude and supplementing waiters' wages in Israel. Social norms and gratitude are statistically significant in the Czech Republic as well. However, the low-wage reason has very little support here. Instead, Czech

III: What constitutes good service.

\begin{tabular}{|c|c|c|c|c|c|}
\hline & all & women & men & regular & non-regular \\
\hline 1. waiters' attentiveness & $94.9 \%$ & $95.5 \%$ & $94.1 \%$ & $95.8 \%$ & $94.4 \%$ \\
\hline 2. waiters' friendliness & $84.8 \%$ & $81.2 \%$ & $89.4 \%$ & $87.3 \%$ & $83.3 \%$ \\
\hline 3. waiters' politeness & $86.8 \%$ & $84.8 \%$ & $89.4 \%$ & $87.3 \%$ & $86.5 \%$ \\
\hline 4. waiters' promptness & $80.2 \%$ & $77.7 \%$ & $83.5 \%$ & $80.3 \%$ & $80.2 \%$ \\
\hline 5. waiters' appearance & $25.4 \%$ & $14.3 \%$ & $40 \%$ & $22.5 \%$ & $27 \%$ \\
\hline 7. food quality & $70.1 \%$ & $70.5 \%$ & $69.4 \%$ & $73.2 \%$ & $68.3 \%$ \\
\hline 8. restaurant appearance & $48.7 \%$ & $49.1 \%$ & $48.2 \%$ & $53.5 \%$ & $46 \%$ \\
\hline number of reasons & 5.3 & 5.1 & 5.6 & 5.4 & 5.3 \\
\hline
\end{tabular}

IV: Why customers tip more for better service.

\begin{tabular}{lccccc}
\hline & all & women & men & regular & non-regular \\
\hline 1. it is fair & $89.8 \%$ & $91.1 \%$ & $88.2 \%$ & $90.1 \%$ & $89.7 \%$ \\
2. to teach waiters & $61.4 \%$ & $62.5 \%$ & $60 \%$ & $54.9 \%$ & $65.1 \%$ \\
3. to show gratitude & $70.6 \%$ & $70.5 \%$ & $70.6 \%$ & $73.2 \%$ & $69 \%$ \\
4. because of social norms & $23.9 \%$ & $24.1 \%$ & $23.5 \%$ & $22.5 \%$ & $24.6 \%$ \\
\hline number of reasons & 2.5 & 2.5 & 2.4 & 2.4 & 2.5 \\
\hline
\end{tabular}


customers who fear a waiter might retaliate in future tip significantly more than other customers.

Contrary to results of Rogelberg et al. (1999) and in accordance with both Bodvarsson and Gibson (1999) and Azar (2010b), virtually all respondents in the present study consider service quality when tipping, though some of them $(22.3 \%)$ react to it in a non-linear way and either only punish poor service or only reward very good service. The reaction to group size and visiting frequency is less clear. Most customers (68\%) seem to consider neither group size, nor visiting frequency when tipping. Of course, this may be an artifact of the rounding to multiples of 10 CZK. If this was the case then most customers' premium for dining in groups or in often revisited restaurants would be very small. Moreover, it would be uncertain whether the premium is positive or negative since some customers raise their tips while others lower them when in groups or in often visited restaurants. Overall, there is little evidence that most customers tip differently when in groups or in revisited restaurants in the present data.

The definition of good service is very similar to what Bodvarsson and Gibson (1999) found in the USA and Canada. The only difference is that Czech customers (at least Czech women) considered the amount of work done and waiters' appearance much less than their US and Canadian counterparts. The reasons why Czech customers reward waiters with higher tips when the service is better are very similar to what Azar (2010b) found in the USA and Israel. The most striking difference between the Czech Republic and the USA and Israel lies in tipping to teach waiters that their tips depend on service quality provided. While only $40 \%$ of Americans and $36 \%$ of Israelis marked this reason, it was marked by $61.4 \%$ of Czech respondents.

Overall, these findings support the notion that interpersonal relationship and social norms might strongly influence human behavior even in the economic context. They might suggest that practice of giving gratuities could partially substitute for the need for management oversight because customers determine the amount tipped by the quality of the service provided. However, it is not certain whether the difference in tips for excellent and poor service is sufficient to eliminate the need for managerial supervision altogether because tips are rather small in the Czech Republic and must be supplemented with wages. Moreover, some customers may tip even when the service is poor to keep the social norm and to avoid waiters' retaliation. This study does not address this question directly and thus it remains to be answered by a following study.

Finally, the limitations of the present study should be noted. The limitations are the same as in the papers on which this study is methodologically based. The first limitation is that all respondents were young university students living in the same city. Thus the results may not be easily generalizable for other social groups in the Czech Republic. The second limitation is that all data were obtained by a survey. Therefore, the results show how respondents want to act, but it is possible that they will behave differently in the real situation. Therefore, further research is needed to obtain the definitive conclusions.

\section{CONCLUSION}

The present study explores what motivates Czech restaurant customers to tip: why they tip and how their tips depend on service quality, patronage frequency, and group size. It supports the major results of previous studies by Bodvarsson and Gibson (1999) and Azar (2010b), and partially also the results of Rogelberg et al. (1999). However, there are many minor differences in tipping motivation and behavior between Czech and American, Canadian, and Israeli customers. Czech restaurant customers tip mostly for positive reasons: to show their gratitude for service and to follow social norms which most of them follow from belief and not because of social pressure. However, one negative reason for tipping is strongly felt by Czech customers too: they tip to avoid feeling guilty when not tipping. Unlike American and Israeli consumers, only a few Czechs tip to supplement waiters' low wages. Czech customers with more motives for tipping tip more. Especially customers who tip to keep social norms and to show their gratitude tip more than others. Unlike Americans and Israelis, Czech customers who fear that waiters might retaliate in the future if not tipped tip more too. On the other hand, there is little evidence that the customers who claim that they tip to supplement waiters' low wages do actually tip more than others.

There is strong evidence that Czech customers tip more for better service. Panel regression on the aggregate data shows that in general customers reduce their tips by $5 \%$ if the service is poor and raise their tips by $5 \%$ if the service is very good. This holds true on an individual level too. Simplified policy capturing shows that the vast majority of customers consider service quality when tipping. Some customers only punish poor service but tip the same for satisfactory and very good service; others only reward very good service but tip the same for that which is poor or satisfactory. However, most customers tip least for poor service, more for satisfactory service, and most for very good service.

Most Czech customers tip more for better service because it is fair and to show their gratitude, and not because it is required by social norms. Unlike Americans and Israelis, almost two thirds of Czech customers tip more for better service to motivate waiters to provide good service in the future. 
The notion of service quality is similar in the Czech Republic to that in the USA and Canada. Waiters' friendliness, promptness, and attentiveness are the most important characteristics of service quality. However, the amount of work done and waiters' appearance is much less important in the Czech Republic than in the USA and Canada. As elsewhere, Czech customers also tip to reward factors that are beyond the control of waiters such as food quality and restaurant appearance and cleanliness, which suggests that tips are a reward for the whole dining experience and not only for the service provided by waiters.

The impact of group size on tips is uncertain. Panel regression on aggregate data shows that customers, on average, tip more when with a friend than alone. However, most customers individually tip the same regardless whether they are alone or with a friend. Only a minority of customers tip more with a friend while other minority does the opposite. The aggregate effect seen in the panel regression seems to be caused by the fact that the first minority is slightly more represented in the data than the latter. The visiting frequency probably has no effect on tipping since it is mostly respondents who visit no restaurants frequently who claim they tip more in restaurants they visit often.

\section{REFERENCES}

AZAR, O. H. 2007a. Do People Tip Strategically, to Improve Future Service? Theory and Evidence. Canadian Journal of Economics/Revue Canadienne d'économique, 40(2): 515-527.

AZAR, O. H. 2007b. The Social Norm of Tipping: A Review. Journal of Applied Social Psychology, 37(2): 380-402.

AZAR, O. H. 2009. Incentives and Service Quality in the Restaurant Industry: The Tipping-service Puzzle. Applied Economics, 41(15): 1917-1927.

AZAR, O. H. 2010a. Do People Tip Because of Psychological or Strategic Motivations? An Empirical Analysis of Restaurant Tipping. Applied Economics, 42(23): 3039-3044.

AZAR, O. H. 2010b. Tipping Motivations and Behavior in the US and Israel. Journal of Applied Social Psychology, 40(2): 421-457.

BARKAN, R. and ISRAELI, A. 2004. Testing Servers' Roles as Experts and Managers of Tipping Behaviour. The Service Industries Jounal, 24(6): 1-18.

BODVARSSON, Ö. B. and GIBSON, W. 1999. An Economic Approach to Tips and Service Quality: Results of a Survey. The Social Science Journal, 36(1): 137-147.

BODVARSSON, Ö. B. and GIBSON, W. A. 1994. Gratuities and Customer Appraisal of Service: Evidence from Minesota Restaurants. The Journal of Socio-Economics, 23(3): 287-302.

BODVARSSON, Ö. B. and GIBSON, W. A. 1997. Economics and Restaurant Gratuities: Determining Tip Rates. American Journal of Economics and Sociology, 56(2): 187-203.

CONLIN, M., LYNN, M. and O'DONOGHUE, T. 2003. The Norm of Restaurant Tipping. Journal of Economic Behavior $\sigma$ Organization, 52(3): 297-321.

FREEMAN, S., WALKER, M. R., BORDEN, R. and LATANE, B. 1975. Diffusion of Responsibility and Restaurant Tipping: Cheaper by the Bunch. Personality and Social Psychology Bulletin, 1(4): 584-587.

KAHNEMAN, D., KNETSCH, J. L. and THALER, R. 1986. Fairness as a Constraint on Profit Seeking: Entitlements in the Market. The American Economic Review, 76(4): 728-741.

KVASNIČKA, M. and SZALAIOVÁ, M. 2015. Determinant of Gratuity Size in the Czech Republic: Evidence from Four Inexpensive Restaurants in Brno. Review of Economic Perspectives, 15(2): 121-135.

LYNN, M. 2003. Restaurant Tips and Service Quality: A Weak Relationship or Just Weak Measurement. International Journal of Hospitality Management, 22(3): 321-325.

LYNN, M. 2006. Tipping in Restaurants and Around the Globe: An Interdisciplinary Review. In: ALTMAN, M. (Ed.). Handbook of Contemporary Behavioral Economics: Foundations and Developments. M. E. Sharpe Publishers, pp. 626-643.

LYNN, M. and GRASSMAN, A. 1990. Restaurant Tipping: An Examination of Three 'Rational' Explanations. Journal of Economic Psychology, 11(2): 169-181.

LYNN, M. and LATANÉ, B. 1984. The Psychology of Restaurant Tipping. Journal of Applied Social Psychology, 14(6): 549-561.

LYNN,M. and MCCALL, M. 2000. Gratitude and Gratuity: A Meta-Analysis of Research on the Service-Tipping Relationship. The Journal of Socio-Economics, 29(2): 203-214.

ROGELBERG, S. G., PLOYHART R. E., BALZER, W. K. and YONKER, R. D. 1999. Using Policy Capturing to Examine Tipping Decisions. Journal of Applied Social Psychology, 29(12): 2567-2590. 